\title{
Burkholderia cepacia aisladas de variedades de ñame con actividad antimicrobiana contra Colletotrichum gloeosporioides
}

\section{Burkholderia cepacia isolated from varieties of Yam with antimicrobial activity against Colletotrichum gloeosporioides}

\author{
Doncel M, Pedro ${ }^{1}$ Biol, Pérez-Cordero, Alexander² Ph.D. \\ ${ }^{1}$ Universidad de Sucre, Facultad de Educación y Ciencias. \\ Programa de maestría en Biología, Sincelejo Sucre, Colombia. \\ ${ }^{2}$ Universidad de Sucre, Facultad de Ciencias Agropecuarias, grupo de investigación en \\ Bioprospección Agropecuarias. Sincelejo, Sucre, Colombia.
}

Keywords:

Microorganisms endophytes; fungal phytopathogens; metabolite; inhibition.

\section{Palabras Clave:}

Microorganismos endófito; hongos fitopatógenos; metabolito; inhibición.

\begin{abstract}
The present study had as objective in vitro to evaluate the antifungal activity of type compound antibiotic produced by isolated endophytes bacteria from varieties of yam against the mycelial growth of the fungus $C$. gloesporioides. Samples of Yam plants were collected randomly in the form of zig-zag in the Department of Sucre. The collected samples were disinfected surface; subsequently is led to out the isolation, counting and separation of morphotypes of endophytes bacteria through technique of serial over surface of the agar medium. Each to isolated morphotype was used to evaluate in vitro inhibitory activity of cells of endophytes bacteria on the growth of the fungus $C$. gloesporioides. The morphotype of bacteria with greater inhibitory activity were selected to obtain metabolites antibiotic type in two sources of carbon (glucose and mannitol) in three concentrations (0,5; 1,0 and 1,5\%). The morphotype with greater inhibitory activity was 3AT1, the results of the in vitro test showed greater activity when the composite type antibiotic was obtained in the middle with a concentration of $1,5 \%$ glucose. Identification with kitAPI20E results confirm with a $99.9 \%$ of identity with the kind of bacterium Burkholderia cepacia, becoming this compound as a potential biological against the micelal growth of the fungus $C$. gloesporioides, causing the disease known as yam anthracnose in the Department of Sucre.
\end{abstract}

\section{Resumen}

El presente estudio tuvo como objetivo, evaluar in vitro la actividad antifúngica de compuesto tipo antibiótico producido por bacterias endófitas aisladas de variedades de ñame contra el crecimiento micelial del hongo C. gloesporioides. Las muestras plantas de ñame fueron recolectadas aleatoriamente en forma de zig-zag en los sitios de muestreo seleccionados en el departamento de Sucre. Las muestras recolectados fueron desinfectados superficialmente, posteriormente se llevó a cabo el aislamiento, conteo y separación de morfotipos de bacterias endófitas mediante técnica de dilución seriada sobre superficie del medio agar. A cada morfotipo aislado fue utilizado para evaluar in vitro la actividad inhibitoria de células de bacterias endófitas contra el crecimiento del hongo C. gloesporioides. Los morfotipos de bacterias con mayor actividad inhibitoria fueron seleccionados para la obtención de metabolitos tipo antibiótico en dos fuentes de carbono (Glucosa y manitol) en tres concentraciones $(0.5 ; 1,0$ y $1,5 \%)$. El morfotipo con mayor actividad inhibitoria fue $3 A T 1$, los resultados del ensayo in vitro mostró mayor actividad cuando el compuesto tipo antibiótico fue obtenido en el medio con una concentración de $1.5 \%$ de glucosa. Los resultados de la identificación con kit API20E confirman con un $99.9 \%$ de identidad con la especie de bacteria $B$. cepacia, constituyéndose este compuesto como un potencial biológico contra el crecimiento micelal del hongo $C$. gloesporioides, causante de la enfermedad conocida como antracnosis del cultivo del ñame en el departamento de Sucre.
Recibido: 01-10-2016;

Aceptado: 20-03-2017.

Correspondencia autor:

alexpcor@yahoo.com. 


\section{INTRODUCCIÓN}

Según lo manifiesta REINA (2012), el ñame es un cultivo de importancia en las regiones tropicales y subtropicales del mundo, donde es considerado una fuente de alimento (Colombia) es uno de los 12 países del mundo con mayor producción de ñame con 361.034 ton reportadas para 2012 y ocupa el primer lugar en cuanto a rendimiento con 28,3 ton/ha. Este cultivo es la principal fuente de ingresos y empleo rural para pequeños y medianos agricultores. En la Región Caribe Colombiana (zona de mayor producción de ñame) se sostienen al menos 20 mil familias de los departamentos de Sucre, Córdoba y Bolívar. Este producto se comercializa a nivel regional para consumo en fresco y para exportación hacia los mercados de Estados Unidos y Europa, donde es utilizado para alimento de la población latina y uso farmacológico (MÉNDEZ et al., 2013).

Como lo expresa CERON et al., (2006), el ñame, como todo cultivo, también es susceptible a enfermedades que generan fuertes daños en la cantidad producida, rendimiento y calidad del producto final. La antracnosis es una enfermedad que se ha convertido en el principal problema para la producción de ñame, no solo en Colombia sino también en África. En Colombia, la producción de ñame se ha visto afectada por una infección llamada antracnosis causada por el hongo Colletotrichum gloeosporioides. Esta es una de las enfermedades más devastadora, con pérdidas de productividad reportadas hasta de un $80 \%$. Se ha reportado que la antracnosis ha ocasionado pérdidas de productividad hasta de un $80 \%$ (GREEN et al., 2000; 2000; ABANG et al., 2003). Los síntomas de esta enfermedad se manifiestan en tallo, peciolo y hoja como lesiones necróticas que dan una apariencia quemada a la zona afectada; en el tejido foliar aparecen manchas, que pueden ser de formas regulares o irregulares, de color pardo-rojizo con halos cloróticos, lo que reduce la eficiencia fotosintética de la planta y ocasiona disminución en la calidad de los tubérculos (AMUSA et al., 2003). La enfermedad se presenta en el campo cuando coinciden varios factores, entre los que se destacan: la susceptibilidad de la planta, el aumento de la población del patógeno y la alta humedad relativa, fuertes precipitaciones, altas temperaturas, vientos fuertes y alta intensidad de luz (CAMPOS, 2011).

Las pérdidas en los cultivos pueden ser aminoradas por la aplicación directa de varios químicos sobre los tubérculos de ñame. El control de la antracnosis se ha logrado principalmente con fungicidas químicos, tales como benomil, maneb, clorotalonil y mancozeb. El control químico de la enfermedad requiere la aplicación quincenal o mensual de fungicidas, lo que podría ser perjudicial para el medio ambiente, y el uso frecuente de fungicidas químicos podría conducir a la aparición de cepas resistentes a los fungicidas (ONYEKA et al., 2006). La resistencia de la planta huésped a la antracnosis ha sido propuesta como una alternativa viable al uso de fungicidas químicos en el control de la enfermedad (MENDEZ et al., 2013). Sin embargo, estudios han demostrado una alta diversidad genotípica en C. gloeosporioides, lo que sugiere la posibilidad de desarrollar nuevas cepas virulentas que son capaces de superar la resistencia de la planta (ABANG et al., 2003).

El control biológico de enfermedades y plagas de los cultivos que utilizan microorganismos antagonistas ha sido una alternativa ecológica al uso de pesticidas químicos (MOENNE-LOCCOZ et al., 2001) y está siendo ampliamente estudiado con muchas enfermedades de plantas usando una variedad de antagonistas microbianos como parte de los programas de manejo integrado de la enfermedad. Se han propuesto el control biológico empleando microorganismos antagónicos a C. gloeosporioides como las bacterias endófitas, dichas bacterias residen en los tejidos vegetales, principalmente en el espacio intercelular y dentro de los tejidos vasculares sin hacer daño a la planta o proporcionar beneficio a otros residentes microbianos (HALLMANN et al., 1997; KOBAYASHI y PALUMBO, 2000; SEGHERS et al., 2004; ZINNIEL et al., 2002). Endófitos bacterianos tantos Gram-positivas y Gramnegativas se han aislado a partir de varios tipos de tejidos de numerosas especies de plantas (KOBAYASHI y PALUMBO 2000). Diversos microorganismos endófitos muestran actividad antifúngica contra hongos como Fusarium oxysporum y Rhizoctonia solani en el algodón (CHEN et al., 1995), Verticilliumdahliae, Verticilliumsp., y $R$. solani en papa (BERG et al., 2005), Sclerotium rolfsii en los granos (MAHAFFEE et al., 1997), Verticillium longisporum en B. napus (GRANE'R et al., 2003), y $R$. solani, F. oxysporum y Pythium ultimunn en flor de globo (CHO et al., 2002). Ciertas bacterias endófitas pueden comportarse como agentes potenciales de biocontrol contra fitopatógenos vasculares, (CHEN et al., 1995; BERG et al., 2005; MUÑOZ-ROJAS et al., 2005) pero se cuenta con escasa información de endófitos de ñame con actividad inhibitoria sobre el agente causal de la antracnosis C. gloeosporioides, y poca información sobre la producción de metabolitos antimicrobianos con actividad antifúngica.

En busca de estrategias efectivas para el manejo de enfermedades, el control biológico con bacterias endófitas se convierte en una alternativa amigable en la sustitución de productos químicos. Por lo anterior se plantea aislar bacterias endófitas asociadas especies de ñame resistentes a la antracnosis en el departamento de Sucre y evaluar in vitro la actividad antifúngica sobre C. gloesporioides. En este estudio se aislaron bacterias endófitas de plantas de ñame (Dioscórea rotundata) y se evaluó in vitro su capacidad para la inhibición del 
hongo causal de la antracnosis C. gloesporioides, tanto con células vegetativas de la cepa como con su extracto de cultivo crudo filtrado, se identificó la única bacteria con actividad antifúngica significativa como $B$. cepacia.

\section{MATERIALES Y MÉTODOS}

Área de estudio. Las muestras de ñame fueron recolectadas de zonas productoras de ñame en el municipio de Los palmito-Sucre-Colombia, las cuales según georreferenciación se encuentra localizado a $90^{\circ}$ 30 " latitud norte, $95^{\circ}$. 16" longitud este del meridiano de Greenwich, con una temperatura promedio de $27^{\circ}$ C, precipitación anual promedio de $27^{\circ} \mathrm{C}$ y una altura de 175 m.s.n.m

Muestra de estudio. Un total de 10 plantas completa (incluyendo raíces) de 45 días de germinadas de variedades de ñame resistentes a la enfermedad de la antracnosis fueron recolectadas en 10 fincas productoras de ñame, en la cual se realizó un muestreo aleatoriamente en forma de zig-zag. Las muestras fueron rotuladas, almacenas y refrigeradas para su transporte al laboratorio de investigaciones microbiológicas de la Universidad de Sucre y procesadas dentro de las 24 horas después de colectadas.

Aislamiento de bacterias endófitas cultivables. Las raíces, tallo, hojas de cada planta de ñame fueron sometidas a proceso de lavado con agua estéril y cortadas en fragmento de $1 \mathrm{~cm}$ de longitud aproximadamente. El proceso de desinfección superficial de cada tejido fue realizada de la siguiente manera, lavados de cada tejido por separado en agua destilada esterilizada, seguida de agitación por 15 min en solución tampón de fosfato de potasio 0,05 mol L-1, pH 7,0; inmersión por 1 min en alcohol 70\%; agitación por 5 min en solución de hipoclorito de sodio $5 \%$ y Tween $80 \%$; nuevamente inmersión por $1 \mathrm{~min}$ en alcohol $70 \%$ seguida de agitación por 15 min en solución tampón fosfato de potasio $0,05 \mathrm{~mol} \mathrm{L-1,} \mathrm{pH}$ $7,0 \mathrm{y}$, finalmente, el lavado por cuatro veces en agua destilada esterilizada. Para confirmar la esterilización de la superficie de las raíces, alícuota del último lavado fue esparcida en placa conteniendo medio agar $R_{2} A$ e incubada a $28^{\circ} \mathrm{C}$ por 72 horas. La ausencia de crecimiento de bacteria en el medio $R_{2} A$ confirmó que el procedimiento de desinfección superficial fue eficaz en la eliminación de bacterias de la superficie.

Después del proceso de desinfección, cada tejido fue colocado en plato de porcelana y macerado con nitrógeno líquido hasta obtener una mezcla homogénea. De cada homogenizado fue preparado diluciones seriadas las cuales fueron sembradas por difusión sobre la superficie de agar $R_{2} A$ e incubada a $28^{\circ} \mathrm{C}$ por 48 horas. La densidad poblacional de bacterias por tejido (UFC/g de tejido), fue estimada por conteo directo de colonias en placas. Durante el conteo fueron observadas y seleccionadas las colonias que se distinguían en cuanto a forma, aspecto de la superficie, color y tamaño. Los morfotipos seleccionados fueron purificados y mantenidos en agar $\mathrm{R}_{2} \mathrm{~A}$ para su evaluación in vitro contra aislados del hongo C. gloeosporioides.

Hongo. El hongo utilizado para el ensayo antifúngico correspondió a aislados de C. gloesporioides obtenido a partir de hojas de ñame variedad espino (Dioscorea rotundata) provenientes de cultivos en la vereda Castañeda del municipio de Sincelejo, Sucre, Colombia en las coordenadas 9 14 ' $54,39^{\prime \prime} N$ y $75^{\circ} 21^{\prime} 59,57^{\prime \prime O}$ a $172 \mathrm{msnm}$. Este hongo hace parte de la colección del Laboratorio de Investigaciones Microbiológicas de la Universidad de Sucre y previamente fue enviado a la Corporación CorpoGen, de la ciudad de Bogotá Colombia para su identificación a nivel molecular por Secuenciamiento.

\section{Actividad antagónica in vitro de bacterias endófitas} frente a C. gloesporioides. Como técnica de actividad inhibitoria fue utilizado el método de siembra en cultivo dual en PDA-R $\mathrm{R}_{2} \mathrm{~A}(1: 1 \mathrm{v} / \mathrm{v})$ para facilitar tanto el crecimiento bacteriano como del hongo, las cepas bacterianas fueron sembradas en estría a $1 \mathrm{~cm}$ del borde de cada caja de Petri con el medio PDA-R $\mathrm{A}_{2}$, después de incubación a $28^{\circ} \mathrm{C}$ durante 2 días, un bloque de agar $(0,5 \mathrm{~cm}$ de diámetro) con micelio del hongo C. gloeosporioides con tres días de crecimiento, fue inoculado en cada caja de Petri a $4 \mathrm{~cm}$ de cada cepa. El hongo fue inoculado en cajas de Petri sin bacterias como control positivo. Las cajas de Petri fueron incubadas a $28^{\circ} \mathrm{C}$ durante 14 días para examinar el área de inhibición entre el hongo y las cepas bacterianas, como lo reportado por (PALANIYANDI et al., 2011). Luego de la incubación la supresión del crecimiento fúngico fue medida como la zona sin crecimiento del hongo, entre la bacteria y el hongo. Las zonas de inhibición indicaron actividad anti fúngica, y las cepas fueron clasificadas dependiendo al área de inhibición. La taza de inhibición fue expresada con relación al control positivo, se realizaron 3 réplicas de cada par, la cepa con mayor actividad inhibitoria fue seleccionada como la bacteria con mayor potencial antifúngico sobre el hongo para la extracción de metabolitos. El radio de las colonias fúngicas hacia y opuestas a las bacterias también fue medido. El porcentaje de inhibición del crecimiento fue definido usando la siguiente ecuación: Inhibición $(\%)=[(R-r) / R \times 100]$, donde, $r$ es el radio de la colonia fúngica opuesta a la bacteria y $\mathrm{R}$ es el radio del control.

Optimización nutricional para la producción de metabolitos tipo antibióticos. Para determinar la 
mejor fuente de carbono, la cepa 3AT1 (morfotipo 3, aislada de tallo de Dioscorea alata) fue cultivada en medios con diferentes fuentes de carbono, glucosa y manitol. El medio correspondió número 3 , que tiene los siguientes constituyentes: ([(No. 3; $10 \mathrm{~g}$ polipeptona, $1 \mathrm{~g}$ $\mathrm{KH}_{2} \mathrm{PO}_{4}$, y 0,5 $\mathrm{g} \mathrm{MgSO}_{4} 177 \mathrm{H}_{2} \mathrm{O}$ para $\left.1 \mathrm{I},(\mathrm{pH} 6,8)\right](\mathrm{CHO}$ et al., 2007). Para la determinación de la concentración nutricional óptima se utilizó $0,5 \% 1 \%$ y $1,5 \%$ de las fuentes de carbono seleccionadas. El pH del cultivo fue calibrado a 7,0. La cepa fue cultivada en cada vial conteniendo $20 \mathrm{ml}$ de cada medio de cultivo con diferente concentración y fuentes de carbono, fueron cultivadas a $28^{\circ} \pm 3^{\circ} \mathrm{C}$, durante 120 horas, en agitación a $120 \mathrm{rpm}$. La optimización se llevó a cabo mediante el crecimiento de la bacteria en medio No 3 con dos fuentes de carbono.

Extracción de metabolitos. El extracto crudo del cultivo fue obtenido utilizando $5 \mathrm{ml}$ del medio de cultivo a centrifugación durante 20 minutos a 10,000 RPM, se tomó el sobrenadante del cultivo y se pasó por un filtro de membrana de 0,22 , para obtener un extracto libre de células bacterianas.

Actividad antifúngica del extracto crudo purificado. La actividad antifúngica se realizó mediante técnica de difusión en agar, como lo reportado por (ISLAM et al., 2012). La determinación de la actividad antifúngica del extracto crudo purificado, se realizó en medio PDA (20 $\mathrm{mL}$ ), dentro del cual con ayuda con un sacabocados de acero inoxidable estéril se hizo un pozo y luego se le adicionó una gota de agar PDA derretido y el extracto crudo de cada concentración y fuente de carbono fue vertido en el pozo, seguido de la ubicación de dos bloques de agar $(0,5 \mathrm{~cm}$ de diámetro) con el hongo patógeno a la misma distancia. Las cajas fueron incubadas a $28^{\circ} \pm 3^{\circ} \mathrm{C}$ durante 14 días y la actividad inhibitoria de cada concentración y fuente de carbono, fue expresada como el porcentaje de inhibición del crecimiento fúngico, comparado con el control (solo se inoculo medio No 3 sin bacteria en el pozo). Los análisis y mediciones seguirán al método similar anteriormente descrito. Cada tratamiento tuvo 3 repeticiones.

Identificación de bacterias endófitas con actividad antifúngica. Para la identificación de morfotipo de bacterias endófitas con actividad inhibitoria contra C. gloeosporioides, fue utilizado el Kit API 20NE (Biome'rieux, France), el cual es un método de identificación rápida utilizado con frecuencia basado en la degradación de sustratos bioquímicos. Este método es adecuado para identificar los bacilos Gram-negativos en el nivel de las especies mediante la evaluación del perfil de 21 reacciones bioquímicas diferentes. El perfil bioquímico es específico para cada especie dentro de este grupo de bacterias. Estas pruebas se realizaron de acuerdo a las instrucciones del fabricante (Biome'rieux,
Francia). Las pruebas utilizadas incluyen la oxidación de nitrato, la producción de indol, la utilización anaeróbico de la glucosa, arginina y urea, la producción de $\beta$-glucosidasa, proteasa y $\beta$-galactosidasa, así como la utilización de la glucosa, arabinosa, manosa, mannitol, $\mathrm{N}$-acetil -glucosamina, maltosa, gluconato, caprato, adipato, malato, citrato y fenil-etilo. Las galerías de la API se incubaron durante $48 \mathrm{~h}$ a $30^{\circ} \mathrm{C}$ bajo aire ambiente. Los resultados obtenidos fueron interpretados mediante la ayuda del software WebTM API (versión $7,0)$.

\section{RESULTADOS}

Un total de 64 morfotipos de bacterias endófitas fueron aisladas de las variedades de ñame de las cuales seis de ellas mostraron actividad de inhibición in vitro contra Colletotrichum gloeosporioides. Los resultados del ensayo de actividad inhibitoria se observan en la Figura 1 , comprobándose la capacidad de estas bacterias de inhibir el crecimiento de dicho hongo.

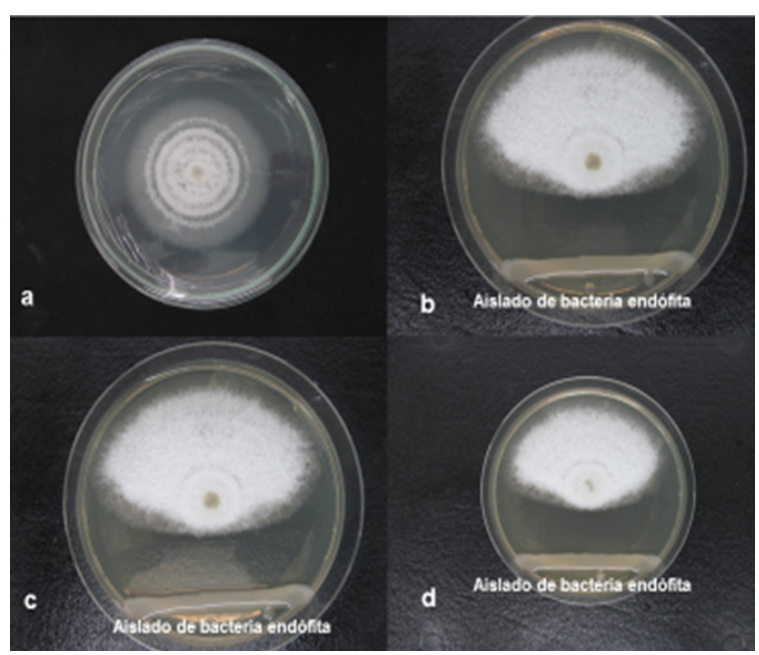

Figura 1. Ensayo in vitro de actividad inhibitoria de bacterias endófitas contra Colletotrichum gloeosporioides. a: Testigo absoluto; b, c y d: Tratamientos bacterias endófitas y $C$. gloesporioides. Fuente Doncel Pedro, 2015.

Los resultados del análisis molecular realizados por el laboratorio CorpoGen de la ciudad de Bogotá, la cepa objeto de estudio, mostró un $100 \%$ de identidad de su longitud con secuencias de ITS, con secuencias almacenadas en banco genómicos mundiales correspondiendo a la especie Colletotrichum gloeosporioides.

El análisis de varianza realizado para la prueba in vitro de actividad inhibitoria de metabolitos tipo antibióticos de bacterias endófitas con dos fuentes de carbono (glucosa y manitol) en tres concentraciones $(0,5 ; 1,0$ y $1,5 \%)$, respectivamente contra $C$. gloeosporioides, 
mostró diferencia significativa para tratamientos ( $p$ valor: <0,0001). La prueba de Tukey muestra que el mayor porcentaje de inhibición se encontró para el tratamiento del metabolito tipo antibiótico cuando se utilizó como fuente de carbono glucosa a $1.5 \%$ de concentración (45,08\%). En la Figura 2 se observa que la menor inhibición fue encontrada para el metabolito tipo antibiótico con fuente de carbono manitol a 05 $(10,28)$ y $1,0 \%(11,17)$ de concentración.

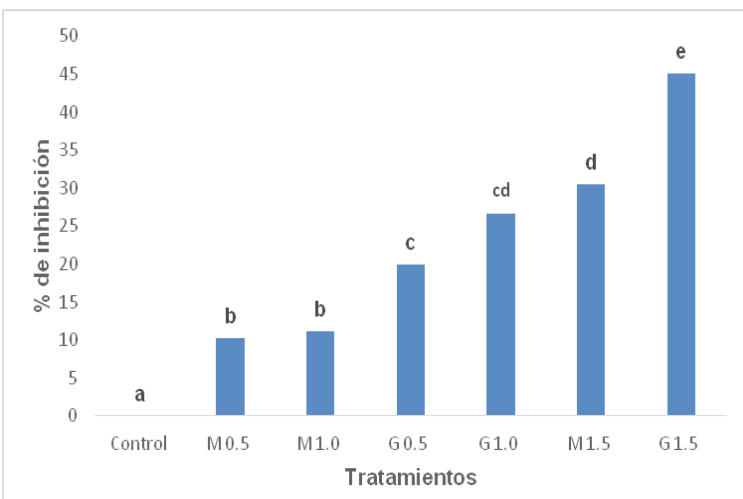

Figura 2. Resultado de prueba Tukey de actividad inhibitoria de metabolitos tipo antibióticos de bacterias endófitas con dos fuentes de carbono, glucosa y manitol a tres concentraciones $(0,5 \% 1 \%$ y $1,5 \%)$ contra C. gloeosporioides. M $\mathbf{0 , 5}$ : manitol 0,5\%, M 1,0: manitol 1,0\%, M 1,5: manitol 1,5\%, G 0,5: glucosa $0,5 \%, \mathbf{G} \mathbf{1 , 0}$ : glucosa $1,0 \%, \mathbf{G} \mathbf{1 , 5}$ : glucosa $1,5 \%$. Medias con una letra iguales no son significativamente diferentes $(p>0,05)$.

Identificación de bacteria endófita. De acuerdo con el resultado del sistema API20E se confirma con un porcentaje de identidad de 99.9, de la cepa 3AT1 la cual fue la que mostró mayor actividad correspondiendo a la especie Burkholderia cepacia, como una bacteria endófita con actividad antifúngica contra C. gloeosporioides agente etiológico responsable de la enfermedad de la antracnosis del cultivo del ñame.

\section{DISCUSIÓN}

Información soportada por MAHENTHIRALINGAM et al., (2005), señalan que el complejo Burkholderia cepacia (CBC, o siglas en inglés $\mathrm{BCC}$ ), o Burkholderia cepacia, antiguamente identificada como Pseudomonas cepacia, es un grupo de bacterias Gram- negativas (no fermentadoras), aerobias y productoras de catalasa. Esta especie de bacteria es considerada un importante patógeno de humanos causante frecuentemente de neumonía en pacientes con enfermedades debilitantes pulmonares como la fibrosis quística o inmunocomprometidos como la enfermedad granulomatosa crónica. Esta bacteria se encuentra comúnmente en el agua y en el suelo y pueden sobrevivir prolongados periodos en ambientes húmedos. Sin embargo estudios llevados a cabos por diversos autores la catalogan como bacteria promotora de crecimiento en plantas y como endófitas.

Burkholderia cepacia es considerada una especie de bacteria importante en el manejo integrado de las enfermedades de las plantas (HERNÁNDEZ et al., 1997), porque tienen la capacidad de crecer colonizando los órganos de las plantas, tales como las raíces y otros tejidos, y producir una gran variedad de metabolitos secundarios tóxicos a hongos y bacterias fitopatógenos, entre los cuales se destacan los sideróforos, antibióticos y alcaloides quinolisidínicos. Estudios realizados en los últimos años, han llegado a la conclusión que la especie de bacteria Burkholderia cepacia adquiere vital importancia en estudios relacionados con la agricultura, debido fundamentalmente a la producción de una amplia gama de metabolitos activos, que influyen positivamente en el crecimiento y desarrollo saludable de las plantas (BEVIVINO et al., 2000).

De otra parte, estudios llevados a cabo por PÉREZ et al., (2016), sobre la presencia de bacterias endófitas asociadas a especies de pasturas en ambientes contaminados con mercurio en el Sur del departamento de Bolívar-Colombia, identificaron a la especie de Burkholderia cepacia KJ935925 de tejido de plantas de Paspalum arundinaceum, con capacidad de resistir in vitro a alta concentración de mercurio.

Otros autores reportan a B. cepacia como una rizobacteria y de acuerdo a lo que señala los estudios realizados por GLICK y BASHAN, (1997), concluyen que las rizobacterias promueven el crecimiento en las plantas mediante diversas estrategias con el propósito de reducir el efecto de algunos fitopatógenos mediante el uso de un sin número de mecanismos entre los que se encuentran: auto competencia, desplazamiento físico del patógeno, secreción de sustancias tipo sideróforos, síntesis de antibióticos y de una variedad de moléculas que pueden inhibir el crecimiento del fitopatógeno y la producción de enzimas que suprimen el patógeno y estimulan el sistema de resistencia de la planta . Para el caso de $B$. cepacia, ha sido considerada una bacteria con un potencial para el control biológico de hongos fitopatógenos (JAYASWAL et al., 1990). La actividad inhibitoria de esta bacteria contra una diversidad de fitopatógenos ha sido atribuida a la producción de metabolitos secundarios como cepacina, pirrolnitrina, altericidina y otros compuestos volátiles y no volátiles aun no identificados (EL-BANNA y WINKELMANN, 1998; QUAN et al., 2006).

Posiblemente uno de los mecanismos involucrados en el antagonismo de mostrado experimentalmente por $B$. cepacia es la producción de compuestos antifúngicos (EL-BANNA et al., 1998). Esta bacteria produce 
una gran cantidad de antibióticos, los cuales poseen actividad antifúngica, como la cepacidina $A$, cepacidina B, xilocandina y pirrolnitrina (ABE y NAKAZAWA, 1993; KAl et al., 2006; ARAQUE et al., 2007; LI et al., 2008). Sin embargo, estos compuestos no han sido muy utilizados en la agricultura debido a su limitado espectro antifúngico y estabilidad. $B$. cepacia puede antagonizar y suprimir diversos fitopatógenos; se le ha reportado que esta bacteria inhibe la germinación de esporas de Alternaria sp., y ataca al hongo Aphanomyces euteiches, el cual causa la podredumbre de raíces de guisantes y alfalfa (ALEMAN et al., 2003). Una de las ultima evidencia que se tiene según PARRA et al., (2009) es que el complejo B. cepacia, aisladas de rizósfera de maíz (SB2, ER3, LG12, N10) cultivado en Venezuela así como otra cepa identificada como CVCM 626, produjeron inhibición en el crecimiento de hongos fitopatógenos como Trichoderma viride mediante la producción de compuestos antifúngico difusibles en el medio, observándose una mayor actividad antifúngica cuando se utilizaron discos de agar con cultivo de $B$. cepacia haciendo contacto con el medio de cultivo.

Con referencia a la actividad antifúngica de $B$. cepacia contra C. gloeosporioides, existe evidencia que la cepa B. cepacia B23 inhibe el crecimiento micelial y la germinación de la espora en un 41 y 100\%, respectivamente de C. gloeosporioides, causante de la antracnosis del cultivo de Papaya (Carica papaya) de Malasia, mediante la producción de una sustancias antifúngica tipo pirrolnitrina (KADIR et al., 2008). Así mismo, estudios llevados a cabo por JAYASWAL et al., (1993), reportan que la actividad antagónica de $B$. cepacia contra el hongo Trichoderma viride puede ser afectada por factores nutricionales debido a las diferencias observadas en el antagonismo al probarse dos medios de cultivos (agar papa dextrosa (PDA) y agar harina de maíz) con fuentes de carbono distintas.

\section{CONCLUSIÓN}

La mayor actividad de inhibición contra C. gloeosporioides se presentó cuando el metabolito tipo antibiótico se obtuvo con la fuente de carbono con glucosa a $1.5 \%$ de concentración $(45,08 \%)$. La bacteria endófita con actividad antifúngica encontrada corresponde a $B$. cepacia, esta bacteria ha sido utilizada como promotora de crecimiento vegetal en diferentes cultivos de interés comercial y como agente de biocontrol de fitopatógenos, sin embargo a la fecha del presente estudio no existe evidencia de la actividad inhibitoria contra $C$. gloeosporioides, hongo causante de la enfermedad conocida popularmente como antracnosis del ñame y que a futuro después de estudios in vivo podría ser una alternativa biológica para el manejo de esta enfermedad en campo en el departamento de Sucre.

\section{Agradecimiento}

Los autores y la Universidad de Sucre expresan sus agradecimientos a la Gobernación del departamento de Sucre y al Fondo Nacional de Ciencias, Tecnología e Innovación (CTe I) del Sistema general de regalíasSGR, por el otorgamiento de recursos económicos por realización de la maestría en Biología y la ejecución de las actividades de Ciencia, Tecnología e Innovación en el marco del proyecto denominado "Implementación de un programa para el desarrollo de productos biotecnológicos para el sector agrícola en el Dpto de Sucre", Código BPIN 2013000100022, celebrado mediante Convenio Especial de Cooperación No 017 de 2014 .

\section{REFERENCIAS}

ABANG, M.M.; WINTER, S.; MIGNOUNA, H.D.; GREEN, K.R.; ASIEDU, R. 2003). Molecular taxonomic, epidemiological and population genetic approaches to understanding yam anthracnose disease. Afr $\mathrm{J}$ Biotechnol 2, 486-496.

ABE, M.; NAKAZAWA T. 1993. Characterization of hemolytic and antifungal substance, cepalycin, from Pseudomonas cepacia. Microbiol Inmunol. 38: 1-9.

ALEMÁN, I.; SÁNCHEZ, J.; SEALEY, M.; ROJAS, J.; LÓPEZ, G. 2003. Empleo de una cepa de Burkholderia cepacia en el control de la mancha azul en la madera de pino caribe (Pinus caribaea). Ciencia. 11: 39-46.

AMUSA, N.; ADEGBITE, A.; MUHAMMED, S; BAIYEWU, R. 2003. Yam disease and its management in Nigeria. African Journals of Biotecnology 2(12):497-502.

ARAQUE, Y.; ALVARADO, L.; CENTENO, S.; RODRÍGUEZ, V.; VITELLI, J. 2007. Actividad antibiótica y antifúngica de B. cepacia provenientes de ambientes nosocomiales. Servicio Autónomo Hospital Universitario "Antonio Patricio Alcalá". Cumaná, Venezuela. Kasmera. 35: 107-17. 
BEVIVINO, A.; DAMALSTRI, C.; TABACCHIONI, S.; CHIARINI, L. 2000. Efficacy of Burkholderia cepacia MCL 7 in disease suppression and growth promotion of maize. Biology and Fertility of Soils, 31 (3-4): 225-231.

BERG, G.; KRECHEL, A.; DITZ, M.; SIKORA, RA.; ULRICH, A.; HALLMANN, J. 2005. Endophytic and ectophytic potato-associated bacterial communities differ in structure and antagonistic function against plant pathogenic fungi. FEMS Microbiol Ecol 51: 215-229.

CAMPOS, R. 2011. Manejo integrado de la antracnosis en ñame. Informe final. Facultad de Ciencias Agropecuaria. Universidad de Córdoba. p38.

CERÓN, R.L.; HIGUERA, M.; B. L.; SÁNCHEZ N.J.; BUSTAMANTE, S.; BUITRAGO, G. 2006. Crecimiento y desarrollo de Colletotrichum gloeosporioides f. alatae durante su cultivo en medios líquidos. Acta Biológica Colombiana, 11 (1), 99-109.

CHEN, C.; BAUSKE, E.M.; MUSSION, G.; RODRIQUEZ-KABANA, R.; KLOEPPER, JW. 1995. Biological control on Fusarium wilt on cotton by use of endophytic bacteria. Biol Control. 5: 83-91.

CHO, S.J.; PARK, S.R.; KIM, M.K; LIM, W.J.; RYU, S.K.; AN, C.L.; HONG, S.Y.; LEE, Y.H.; JEONG, S.G.; CHO, YU.; YUN, H.D. 2002. Endophytic Bacillus sp. isolated from the interior of ballon flower root. Biosci Biotechnol Biochem 66: 1270-1275.

CHO, K. M.; HONG, S. Y.; S. LEE, M.; KIM, Y. H.; KAHNG, G. G.; LIM, Y. P.; KIM, H., YUN, H. D. 2007. Endophytic Bacterial Communities in Ginseng and their Antifungal Activity Against Pathogens. Microbial Ecology. 54:341-351.

EL-BANNA N.; WINKELMANN, G. 1998. Pyrrolnitrin from Burkholderia cepacia: antibiotic activity against fungi and novel activities against Streptomycetes. J Appl Microbiol. 85:69-78.

GRANE'R, G.; PERSSON, P.; MEIJER, J., ALSTRO, M.S. 2003. A study on microbial diversity in different cultivars of Brassica napusin relation to its wilt pathogen, Verticillium longisporum. FEMS Microbiol Lett. 224: 269-276.

GLICK, B.R.; BASHAN, Y. 1997. Genetic manipulation of plant growth promoting bacteria to enhance biocontrol of phytopathogens. Biotechnol. Adv. 15:353-378.

GREEN, K. R.; ABANG, M. M.; ILOBA, C. 2000. A rapid Bioassay for Screening Yam Germplasm for Response to Anthracnose. Tropical Science. 40 (3): 132-138.

HALLMANN, J.; HALLMANN, Q.A.; MAHAFFEE, W.F.; KLOEPPER, J.W. 1997. Bacterial endophytes in agricultural crops. Can J. Microbiol. 43: 895-914.

HERNÁNDEZ, A.; GARCÍA, D.; HERNÁNDEZ, J.; HEYDRICH, M. 1997. Determinación de algunos géneros bacterianos presentes en la rizósfera del cultivo del maíz. Cultivos Tropicales, 18(3):10-14.

ISLAM, MD.; R., Y. T.; JEONG, Y.; LEE, S.; SONG, C. H. 2012. Isolation and Identification of Antifungal Compounds from Bacillus subtilis C9 Inhibiting the Growth of Plant Pathogenic Fungi. Mycobiology. 40(1):59-66.

JAYASWAL, R.; FERNÁNDEZ, M.; SOBROEDER, R. 1990. Isolation and characterization of a Pseudomonas strain that restricts growth of various phytopathogenic fungi. Applied Environmental Microbiology. 56: 1053-8.

KADIR, J.; RAHMAN, M.A.; MAHMUD, T.M.; ABDUL, R.; BEGUM, M.M. 2008. Extraction of antifungal substances from Burkholderia cepacia with antibiotic activity against Colletotrichum gloeosporioides on papaya (Carica papaya L.). Int. J. Agri. Biol., 10: 15-20.

KAI, M.; EFFMERT, U.; BERG, G.; PIECHULLA, B. 2006. Volatiles of bacterial antagonist inhibit mycelial growth of the plant pathogen Rhizoctonia solani. Appl Environ Microbiol. 55: 1053-7.

KOBAYASHI, DY.; PALUMBO, J.D. 2000. Bacterial endophytes and their effects on plants and uses in agriculture. In: Bacon, CW, White, JF, Jr (Eds.) Microbial Endophytes, Marcel Dekker, New York. 
LI, X.; QUAN, C.S.; YU, H.Y.; FAN, S.D. 2008. Multiple effects of a novel compound from Burkholderia cepacia against Candida albicans. FEMS Microbiol Lett. 285: 250-6.

MAHENTHIRALINGAM, E.; T.A.; URBAN, Y. J.; GOLDBERG, B. 2005. The Multifarious, Multireplicon Burkholderia Cepacia Complex. Nature Review Microbiol. 3:144-156.

MAHAFFEE, W.F.; KLOEPPER, J.W. 1997. Temporal changes in the bacterial communities of soil, rhizosphere, and endorhiza associated with fieldgrown cucumber (Cucumis sativus L.). Microb Ecol. 34: 210-223.

MÉNDEZ, Y.; PALENCIA, J.; HERNÁNDEZ, K.; HERNÁNDEZ, E.; BELTRÁN, J. 2013. Reacción de genotipos de ñame (Dioscorea spp) a la antracnosis (Colletotrichum gloeosporioides). Temas Agrarios. 18:(1):34 - 40.

MOENNE-LOCCOZ, Y.; TICHY, H.; O'DONNEL, A.; SIMON, R.; O'GARA, F. 2001. Impact of 2, 4-Diacetylphloroglucinolproducing biocontrol strain Pseudomonas fluorescens $\mathrm{F} 113$ on intraspecific diversity of resident culturable fluorescent Pseudomonads associated with the roots of field-grown sugar beet seedlings. Appl Environ Microbiol 67, 3418-3425.

MUÑOZ-ROJAS, J.; FUENTES-RAMI'REZ, L.E.; CABALLERO-MELLADO, J. 2005. Antagonism among Gluconacetobacter diazotrophicus strains in culture media and in endophytic association. FEMS Microbiol Ecol. 54: $57-66$

ONYEKA, T.J.; PE'TRO, D.; ANO, G.; ETIENNE, S.; RUBENS, S. 2006. Resistance in water yam (Dioscorea alata) cultivars in the French West Indies to anthracnose disease based on tissue culture-derived whole-plant assay. Plant Pathol 55, 671-678.

PALANIYAND, I. S.; YANG, S.H.; CHENG, J.H.; MENG, L.; SUH, J.-W. 2011. Biological control of anthracnose (Colletotrichum gloeosporioides) in yam by Streptomyces sp.MJM5763. Journal of Applied Microbiology 111, 443-455.

PARRA, G. E.; CENTENO, B. S.; ARAQUE, C. Y. 2009. Actividad antifúngica de Burkholderia cepacia aislada de maíz amarillo (Zea mays L.) bajo diferentes condiciones de cultivo. Revista de la Sociedad Venezolana de Microbiología; 29:103-109.

PÉREZ, A.; MARTínEZ, D.; BARRAZA, Z.; MARRUGO, J. 2016. Bacterias endófitas asociadas a los géneros Cyperus y Paspalum en suelos contaminados con mercurio. Rev. U.D.C.A Act. \& Div. Cient. 19 (1):67-76.

QUAN, C.S.; ZHENG, W.; LIU, Q.; OHTA, Y.; FAN, SD. 2006. Isolation and characterization of a novel Burkholderia cepacia with strong antifungal activity against Rhizoctonia solani. Appl Microbiol Biotech. 72: 1276-84.

REINA, A.Y. Documentos de trabajo sobre economía regional: El cultivo del ñame en el Caribe Colombiano. Banco de la Republica, Centro de Estudios económicos Regionales-CEER. Cartagena, Colombia, p34.

SEGHERS, D.; WITTEBOLLE, L.; TOP, E.M.; VERSTRAETE, W.; SICILIANO, S.D. 2004. Impact of agricultural practice on the Zea mays L. endophytic community. Appl Environ Microbiol. 70: 1475-1482

ZINNIEL, D.K.; LAMBRECHT, P.; HARRIS, N.B.; FENG, Z.; KUCZMARSKI, D.; HIGLEY, P.; ISHMARU, C.A., ARUNAKUMARI, A.; BARLETTA, R.G.; VIDAVER, A.K. 2002. Isolation and characterization of endophytic colonizing bacteria from agronomic crops and prairie plants. Appl Environ Microbiol. 68: 2198-2208. 